\title{
LA INVESTIGACIÓN SOBRE LA ENSEÑANZA DE LENGUAS EN UN CONTEXTO TRANSFRONTERIZO: ANÁLISIS DEL PERFIL PROFESIONAL DOCENTE
}

\author{
Maristela Alves de Souza DINIZ* \\ Paloma Castro PRIETO**
}

- RESUMEN: En el proceso de construcción de la identidad del profesional del docente, intervienen unas prácticas sociales y profesionales en las que participa. Éstas, a su vez, se ven afectadas por el contexto en el que se encuentran inmersas. En este artículo, nos situamos en un contexto transfronterizo de la región Brasil-Perú-Bolivia para abordar el perfil profesional del docente desde el análisis de sus percepciones. La finalidad de nuestro análisis es identificar aquellos elementos de la competencia plurilingüe que subyacen a su perfil profesional docente, lo que nos permitirá reflexionar sobre las potencialidades que ofrece el contexto transfronterizo para la construcción de una identidad profesional en la perspectiva de la educación plurilingüe. Nos situamos en el ámbito de la Didáctica de las Lenguas y la Literatura para abordar unos conceptos claves relacionados con la educación plurilingüe. Hemos identificado que los docentes son conscientes de las potencialidades del contexto y desarrollan unas prácticas pedagógicas que favorecen el desarrollo de la competencia plurilingüe.

- PALABRAS-CLAVE: Identidad profesional. Contextos de frontera. Docente de lenguas. Educación plurilingüe.

\section{Introducción}

Los contextos se nos presentan cada día más plurales y en la literatura van aflorando nuevos términos que buscan expresar o significar toda esta realidad plural. En el caso de las palabras "multilingüe" y "multicultural", los estudios que abordan estos conceptos los definen como la coexistencia de distintas lenguas y culturas en un mismo territorio y como el conocimiento que los individuos tienen de estas lenguas y culturas (CONSEJO DE EUROPA, 2002; BEACCO; BYRAM, 2007; PIÑEIRO; GUILLÉN; VEZ, 2010; NUSSBAUM; UNAMUNO, 2014). Aunque bajo estos términos subyace la idea de

\footnotetext{
Universidade Federal do Acre (UFAC), Rio Branco, Acre, Brasil y Universidad de Valladolid (UVA), Valladolid, España.malvesdiniz1@gmail.com. ORCID: 0000-0001-9841-3847

** Universidad de Valladolid (UVA), Departamento de Didáctica de la Lengua y la Literatura, Valladolid, España. pcastro@dlyl.uva.es. ORCID: 0000-0002-6644-8364.
} 
su preservación, en especial de aquellas lenguas minoritarias, porque se considera que cada una de ellas tiene su debido valor e importancia; desde nuestro punto de vista, son conceptos muy estáticos, pues no se tienen en cuenta la interacción entre lenguas y culturas.

Asimismo, surgen otros términos en el contexto europeo, tales como: "plurilingüismo", "pluricultural” y "competencia plurilingüe”. El plurilingüismo se concibe, por un lado, como una capacidad del individuo para hacer uso de varias lenguas $\mathrm{y}$, por otro, como un valor para vivir en sociedad. Bajo este concepto subyace la idea de movilización, dinamismo, lo que requiere que el individuo desarrolle unas capacidades específicas (competencia plurilingüe) que le permita hacer uso de las diversas lenguas y culturas que componen su repertorio lingüístico en una acción intercultural. De esta forma, el aprendizaje de otras lenguas se concibe como más eficiente. Además, este proceso es también reflexivo por cuanto que el individuo se conciencia del valor que tienen las lenguas, afectando su forma de interactuar con otras personas. El fomento del plurilingüismo es una de las medidas del Consejo de Europa para atender a la diversidad de lenguas y culturas.

La pluralidad lingüístico-cultural es aun más evidente en los contextos fronterizos donde la interacción entre los individuos es constante. En estos espacios se forman procesos complejos de relaciones que están marcados por su propio dinamismo (ARRIAGA-RODRÍGUEZ, 2012).

Estos lugares, esencialmente multilingües y multiculturales, son favorecedores del aprendizaje de lenguas al estar las personas en contacto con diversas lenguas y culturas. De este modo, las prácticas de aula del profesorado de lenguas se ven afectadas por el propio contexto. Por ello, partimos de la premisa de que estos docentes de lenguas van desarrollando unas prácticas translingüísticas y transculturales que conforman su identidad profesional.

Ante esta situación, centramos la atención en el docente de lenguas que se encuentra en un contexto transfronterizo. Relacionamos el término transfronterizo con los conceptos de frontera y fronterizo considerándolos espacios formados socialmente. Se trata de zonas singulares construidas por los propios individuos que las constituyen y que en la misma medida van caracterizándolos. Estos espacios se caracterizan por prácticas sociales discontinuas si bien igualmente complementarias.

En el proceso de construcción de su identidad profesional, el docente incorpora elementos orientados a potenciar el aprendizaje de lenguas de su alumnado. Este estudio tiene como finalidad identificar aquellos elementos de la educación plurilingüe que subyacen al perfil del docente de lenguas que actúa en un contexto transfronterizo. Para ello, indagamos en las percepciones de los profesores de lenguas de las escuelas de la región transfronteriza que está compuesta por las siguientes localidades: Estado de Acre (Assis Brasil, Brasil), el Departamento de Pando (Cobija, Bolivia) y la Provincia de Madre de Dios (Iñapari, Perú). 
Conocer este perfil nos permitirá reflexionar sobre las potencialidades que ofrece el propio contexto transfronterizo para la construcción de una identidad profesional del docente en la perspectiva de la educación plurilingüe.

\section{Marco teórico}

Enseñar lenguas y culturas se ha constituido desde siempre un reto porque no se trata solamente de transmitir meras estructuras lingüísticas a los estudiantes sino que se trata de dar a conocer otras formas de decir y de ver el mundo. Y en los días actuales este reto se nos presenta aun más desafiador, pues significa ir más allá de mostrar algo a alguien, dar ejemplos o hacer que alguien aprenda algo.

Los contextos, cada día más plurales, exigen de los profesionales que se dedican a la enseñanza de lenguas múltiples competencias para atender al alumnado y solucionar los problemas que surgen en el aula, tales como las actitudes intolerantes en función de miradas superficiales y llenas de estereotipos de los estudiantes cuando entran en contacto con nuevas lenguas y culturas ya sea en los contextos formales de aprendizaje o en un dado contexto social.

Los profesores de lenguas van construyendo una identidad profesional que los caracteriza. Esta identidad está marcada por la formación académica que han recibido y también por el propio contexto en el que actúan. En contextos plurales, como son los contextos transfronterizos, la identidad es aún más compleja.

Hall, Silva y Louro (2006, p. 24) señala que plantear una definición de identidad es una tarea un tanto difícil porque se trata de un concepto muy complejo. Sin embargo, nos conduce a una definición de identidad entendida como una "celebración móvil", provisoria, variable y problemática. Para este autor, la identidad del hombre moderno se ha fragmentado, si antes eran "plenamente unificadas y coherentes ahora ya se convirtieron en plenamente descentradas".

Tal y como mencionan Hall, Silva y Louro (2006) y Bauman (2005) las identidades se han ido fragmentando en función de los cambios sociales. Para los mencionados autores, estos cambios son responsables del descentramiento del sujeto y de la crisis de identidad del hombre moderno.

En lo que respeta a la identidad profesional, Balduzzi y Egle (2010, p. 67) observan que su construcción es un proceso dinámico y complejo, que se inicia en la formación académica y se extiende a lo largo de la trayectoria y actuación profesional. Para estas autoras, en este proceso el individuo "[...] se define a sí mismo en relación con su espacio de trabajo y un grupo colectivo profesional de referencia, es decir, en términos de ocupación, oficio o profesión y respecto de aquellos que la ejercen."

Esta identidad profesional es construida individual y colectivamente, o tal y como explica Bauman (2005) se da a partir de la formación del uno más el otro, es decir, en relación, son construcciones históricas dinámicas situadas dentro de un contexto social e inexistente fuera de él. 
Morales Ortega (2016, p. 20) señala que las identidades se "crean en una época y en un espacio concreto". Por esta razón, este autor afirma que es importante "[...] comprender los espacios y el contexto social en el que los individuos se relacionan entre sí y entender los efectos que estos cambios históricos producen en la construcción de las identidades individuales y colectivas."

El contexto en el que insertamos esta investigación, al que llamamos transfronterizo, marcado por su dinamismo, se concibe como un espacio que está más allá de uno u otro lugar de la frontera. Es el contexto en el que todos se implican mutuamente, se reconocen, se valoran, se encuentran y cooperan, comparten y generan prácticas translingüísticas y transculturales.

En el caso concreto de la región transfronteriza del Estado de Acre, ubicado en la tríplice frontera Brasil-Perú-Bolivia, tierras anteriormente pertenecientes al territorio boliviano, es el último Estado incorporado al territorio brasileño tras una serie de acuerdos diplomáticos y enfrentamientos entre Brasil y Bolivia que termina tras la victoria de Brasil en 1903 con la Guerra de Acre.

Las ciudades situadas en las zonas limítrofes presentan unas características socioculturales muy peculiares debido al encuentro de lenguas y culturas brasileña, nativas, bolivianas y peruanas. Además de otras culturas extranjeras que componen este mosaico en virtud de ser esta zona un camino de acceso al pacífico y también una zona de libre comercio.

Actualmente, el portugués y el español son los idiomas hablados por la mayoría de los habitantes. Sin embargo, hay que considerar las otras lenguas que circulan en estos espacios: el portuñol ${ }^{1}$ que es una variedad compartida tanto por brasileños, bolivianos y peruanos; el inglés que es ofertado de forma obligatoria en la Enseñanza Secundaria en las escuelas de la frontera; las lenguas indígenas como el quechua y el aimara; la lengua originaria cavineña ${ }^{2}$ que es ofertada a los estudiantes de las escuelas bolivianas; y también las otras lenguas indígenas habladas por un número más reducido de pueblos originarios (manchineri) ${ }^{3}$ ubicados en la región brasileña de la tríplice frontera.

Creemos que la enseñanza de lenguas en este contexto transfronterizo, donde existe una gran movilización de lenguas y culturas, debe integrar planteamientos de la educación plurilingüe mediante prácticas de aula orientadas hacia al desarrollo de la competencia plurilingüe del alumnado.

Unos planteamientos orientados a favorecer el encuentro con el otro, considerar las lenguas y culturas diversas, reconocer el valor de cada uno y comprender a partir de las diferencias. Un planteamiento de enseñanza de lenguas en esta perspectiva es,

\footnotetext{
El portuñol es una lengua de contacto utilizada por hablantes del portugués y del español que se encuentran en las regiones fronterizas de Brasil con los países hispanohablantes.

2 La lengua cavineña pertenece a la familia lingüística Tacana y es una de las lenguas originarias de Bolivia. Su oferta pasa a ser obligatoria en el currículo escolar de los departamentos bolivianos de Beni y Pando cuando se realiza la reforma educativa en Bolivia en el año 2010 reconociendo este país como intracultural, intercultural y plurilingüe.

3 Los manchineri son pueblos originarios que viven en el territorio brasileño ubicado en la frontera con Perú y Bolivia. Pertenecen a la familia lingüística aruak.
} 
desde nuestro punto de vista, más igualitario y más eficaz porque se tiene en cuenta las distintas lenguas que componen el repertorio lingüístico de los individuos que se mueven en este contexto transfronterizo.

\section{Metodología}

La finalidad de este estudio es contribuir a la construcción de una identidad profesional del docente de lenguas que atienda a la educación plurilingüe. Para ello, indagamos en su perfil profesional docente a través de sus concepciones sobre la enseñanza y mediante la identificación de los elementos de la competencia plurilingüe que subyacen a este perfil. Teniendo esto en cuenta establecemos los siguientes objetivos:

- Identificar los elementos de la competencia plurilingüe que subyacen a la gestión de la propia práctica y compromiso como docente.

- Identificar los elementos de la competencia plurilingüe que subyacen a la gestión de la integración del espacio de aula y de la comunidad escolar.

Para identificar los elementos de la competencia plurilingüe del perfil profesional del docente de lenguas que subyacen a la gestión de los elementos anteriormente mencionados, hemos optado por explorar las percepciones del profesorado adoptando un enfoque metodológico que lo ubicamos dentro del paradigma cualitativo interpretativo.

Nos situamos desde un paradigma cualitativo con el propósito de comprender una realidad desde las propias percepciones de los sujetos implicados en el proceso de enseñanza-aprendizaje de lenguas. Esta opción se ve apoyada en la aportación de Flick (2015) cuando señala que la investigación cualitativa nos permite acercarnos al mundo externo a través del análisis de las percepciones y experiencias de los individuos mientras éstas se producen.

Para la recogida de los datos, hemos diseñado una entrevista de tipo semiestructurada. En cuanto técnica, la entrevista nos permite la recogida sistemática de informaciones. Además, tal y como nos menciona Kvale (2011) este tipo de instrumento nos permite aproximar a la realidad de los informantes a través de sus propias palabras, conociendo sus propias perspectivas.

Hemos considerado pertinente para el caso elaborar unas preguntas guías pero, a la vez, dar a los informantes mayor libertad para expresar sus percepciones y a partir de ellas formular otros interrogantes, procedimiento que, según menciona (BISQUERRA, 2014, p. 337), "permite ir entrelazando temas e ir construyendo un conocimiento holístico y comprensivo de la realidad". El carácter flexible de la entrevista nos ha permitido realizar ajustes durante su realización favoreciendo el proceso interactivo entre entrevistador y entrevistados. 
Dicho procedimiento nos ha permitido recoger informaciones de los docentes con respeto a su forma de actuar y percibir aquellas situaciones conflictivas que ocurren en su aula; sus percepciones con respeto a la motivación, concienciación y receptividad de los estudiantes hacia el aprendizaje de lenguas; la utilización de recursos para motivar el aprendizaje y la promoción de la autonomía en los estudiantes así como con respeto al trabajo colaborativo entre sus pares.

Las entrevistas fueron aplicadas a docentes de lenguas que actúan en el contexto transfronterizo de la tríplice frontera Brasil-Perú-Bolivia. Establecimos como criterios de inclusión de los participantes los docentes que actúan en escuelas de frontera con la enseñanza de lenguas, materna o extranjera; y como criterios de exclusión de los informantes docentes que viven en áreas no situadas en contextos de frontera y trabajan con otras disciplinas ajenas al área de lenguas.

Aplicando estos criterios, contamos con 03 (tres) profesores de lenguas como informantes que, para este caso, los identificamos como P1, P2 y P3.

El informante, identificado como P1, es bilingüe (portugués-español) su trayectoria académica tuvo inicio en Perú (Enseñanza Fundamental y Secundaria) y ha finalizado en Brasil, concluyendo su formación universitaria en Letras Portugués en la Universidad Federal de Acre. Procede y reside en el contexto de actuación, ciudad de Assis Brasil, Acre-Brasil.

El informante, identificado como P2, es bilingüe (quechua-español) es proficiente en la lengua cavineña, toda su formación académica se dio en territorio boliviano, con formación en Comunicación y Lenguaje. Actúa como profesor de Lengua Española y Lengua Cavineña. Es procedente de un ámbito externo a la comunidad de actuación; sin embargo, reside hace más de una década en el local, Cobija, Departamento de Pando-Bolivia.

El informante, identificado como P3, también bilingüe en quechua y español, recibió su formación en territorio peruano, se graduó en Comunicación y Lenguaje y, actualmente, ejerce la profesión de profesor de Lengua Española. Es procedente de un ámbito externo a la comunidad de actuación, y se instaló recientemente en la comunidad escolar de Iñapari, Madre de Dios-Perú.

Para el análisis de los datos nos hemos apoyado en las aportaciones de Bisquerra (2014), Batthyány y Cabrera (2011) y Bardin (1986). Hemos optado por realizar el análisis de contenido que estos autores definen como una técnica de investigación donde los datos son descritos de forma objetiva y sistemática.

El análisis se ha orientado en torno a dos ejes: 1) El perfil del profesorado de lenguas en lo que respeta a su gestión de la práctica pedagógica y 2) El perfil del profesorado de lenguas en lo que respeta a la gestión de la integración del espacio de aula y de la comunidad.

Partiendo de estos dos ejes, definimos cuatro categorías: reflexión de la propia práctica, compromiso como docente, interacción que establece con el alumnado e implicación en la comunidad escolar. 
Para la definición de la primera categoría, reflexión de la propia práctica, hemos considerado la práctica reflexiva que Perronoud (2007, p. 41) sitúa en el oficio del enseñar. Este autor argumenta que la práctica reflexiva es un compromiso que se asienta por un lado en un "polo pragmático", mediante el desarrollo de actitud, y por otro lado en un "polo de identidad" mediante la formación de una identidad particular.

Por lo tanto, bajo la categoría reflexión de la propia práctica recogemos aquellos enunciados que dan cuenta de las reflexiones sobre su propia práctica, es decir, lo que hace y cree que debe hacer para alcanzar sus objetivos de enseñanza en términos de apropiación de elementos lingüísticos y culturales, despertar el interés y motivación del alumnado para aprender lenguas e intervenir en situaciones de conflictos en el aula.

Para la definición de la segunda categoría, compromiso como docente, hemos tenido en cuenta la noción de compromiso e implicación que Traver Marti (2011) sitúa en la zona de la caracterización del docente comprometido con una enseñanza de calidad y a servicio de la justicia social.

Traver Marti (2011, p. 95) citando a Gale y Densmore (2007) argumenta que los docentes deben ejercer un papel político con vistas a fomentar "la democracia radical, la disposición crítica para con la sociedad y el activismo político."

Así pues, bajo la categoría compromiso como docente recogemos los enunciados que dan cuenta de aquellas prácticas del profesorado orientadas a fomentar el aprendizaje del alumnado desde una conducta consciente donde se primen las buenas prácticas sociales.

Para la definición de la tercera categoría, interacción que establece con el alumnado, hemos tenido en cuenta la interacción entre docentes-discentes en contextos pedagógicos que Artavia (2005) sitúa como el aspecto relacional comunicativo-afectivo. Estos aspectos son considerados por esta autora como piedras basilares para el desarrollo integral del individuo.

Según establece Richards (2005) es la relación entre profesor-alumno una de las interacciones más importantes en el contexto escolar dada su naturaleza bidireccional que comprende un proceso de implicación mutua.

De este modo, bajo la categoría interacción que establece con el alumnado recogemos los enunciados que dan cuenta de los aspectos relacionados con la capacidad del profesor de lenguas para interactuar con el alumnado y su capacidad para crear vínculos que permitan establecer una relación de confianza, aprecio, consideración por el otro, tolerancia y respeto.

Para la definición de la cuarta categoría, implicación con la comunidad escolar, hemos tenido en cuenta la noción de trabajo colaborativo que Fernández Tilve y Malvar Méndez (1999) consideran como elemento potenciador para el desarrollo profesional. Se trata de prácticas intencionadas y orientadas hacia al alcance de metas comunes, prácticas moldeadas por el diálogo y empeño profesionales.

Por lo tanto, bajo la categoría implicación con la comunidad escolar recogemos aquellos enunciados que dan cuenta del compromiso del docente y su disponibilidad para la interacción con los miembros que conforman la comunidad escolar, así como la disponibilidad para colaborar con los pares y organizar actividades en el centro escolar. 
Para esas categorías establecimos unas sub categorías de análisis guiándonos por el proceso sistemático de la codificación axial (STRAUSS; CORBIN, 1990). El criterio utilizado para establecer dichas sub categorías ha sido la separación de las unidades de análisis procedentes del corpus documental mediante la ordenación por proximidad temática permitiéndonos ver diferentes dimensiones dentro de una misma categoría. Así, hemos establecido las siguientes sub categorías de análisis:

\section{Reflexión de la propia práctica}

- Se apropian de conocimientos lingüísticos-culturales diversos;

- Comparten su lengua y cultura;

- Motivan sus alumnos al aprendizaje de lenguas y culturas;

- Despiertan el interés de los alumnos para el aprendizaje de lenguas;

- Intervienen en situaciones de conflictos.

\section{Compromiso como docente}

- Orientan la enseñanza de lenguas para la formación de individuos más humanos;

- Fomentan el aprendizaje autónomo de las lenguas.

\section{Interacción que establece con el alumnado}

- Interactúa con los alumnos;

- Construyen vínculos afectivos con los alumnos.

\section{Implicación con la comunidad escolar}

- Participan de las actividades que realiza su centro educativo e se implican en los problemas que los afectan;

- Interactúan y colaboran con otros profesionales de su centro educativo.

\section{Discusión de los datos}

En cuanto a la categoría reflexión sobre la propia práctica, los datos revelan que los docentes de lenguas son conscientes de que necesitan apropiarse de otras lenguas, incluso aquellas que forman parte de su realidad fronteriza. Asimismo, todos los informantes declaran que utilizan su lengua materna para potenciar el aprendizaje lingüístico-cultural de sus alumnos realizando ejemplificaciones y comparaciones con la lengua que enseñan, como se puede ver en las siguientes manifestaciones: ${ }^{4}$

4 Las inferencias presentadas en este artículo son parte del corpus documental utilizado en el proyecto de investigación de nuestra Tesis Doctoral desarrollada dentro del Programa de Doctorado en Investigación Transdisciplinar en Educación de la Universidad de Valladolid. Hemos optado por presentar las inferencias en la lengua original en que 
Por exemplo: ...Tive alunos peruanos aqui e em determinado conteúdo... _Professor, isto está errado! Manifestam-se no mesmo momento... Daí tem que parar para explicar:_Não. É que o espanhol que se ensina aqui é o da Espanha. E muitas coisas diferenciam, não é a mesma coisa. Então muitas coisas na aula são assim... _ a h que legal, não sabia disso. Mesmo falando espanhol há esta diversidade. [P1]

Yo soy de la cultura quechua y pues... hay algunas clases que también comparto en mi lengua originaria, aunque no me puedan entender... Pero, tras que menciono... hablo en mi lengua, les hago la interpretación de lo que significa, entonces... [P2]

Por ejemplo; acá... nosotros que vivimos en la frontera, necesitamos saber el portugués obligatoriamente. Yo, mi persona por ejemplo, necesito saber para poder comunicarme con otras personas de acá de la fronter a y ellos también tienen esta necesidad. Por ejemplo: el inglés es algo básico que le enseñamos para que ellos puedan comunicarse con otras personas. [P3]

Claro, asi es siempre. Tratamos de que ellos convivan [...] Bien. Lo toma de buena manera. A veces se ríen ... bromean y todo. Pero... ahi están... se familiariza con esto. Están familiarizando. [P3]

Asimismo, los datos muestran que los docentes buscan desarrollar en el alumnado un interés por aprender lenguas. Para ellos el aprendizaje de diferentes lenguas permitirá a los estudiantes una mejor comunicación con otras personas y también su ingreso en el mundo laboral además de permitir conocer sobre otras culturas.

Por parte dos professores, de nós, colocamos sempre a importância do dominio do inglês, do espanhol... é fantástico... até para o mercado de trabalho e todo isso... Trazemos esta situação da importância de aprender esta nova lingua que vai contribuir para sua vida, a diversidade cultural que ele pode conhecer através disso... [P1]

O primeiro contato para colocar esta situação é o sexto ano, que é quando já vem o espanhol, e dai já trazemos esta situação da importância de aprender esta nova língua que vai contribuir para sua vida, a diversidade cultural que ele pode conhecer através disso... então... percebemos que muitos aceitam, pero ainda assim encontramos resistência. [P1]

ha sido concedida la entrevista por el informante para evitar cualquier alteración de significado en el proceso de traducción. 
Los que vienen aquí... están aprendiendo otra cultura que es la lengua originaria cavineña... pues se aprende por su propio interés, es una necesidad para comunicarse con otras personas. [P2]

En cuanto al uso de recursos para motivar al alumnado en su aprendizaje de lenguas, el profesor de la escuela brasileña declara que dispone de ellos y realiza actividades que por lo general son motivadoras:

Eu uso a música, o livro didático mesmo, há muitas coisas bacanas, levo o notebook, o data show e coloco situações ... dependendo do conteúdo para mostrar mesmo digamos... a questão das touradas, a festa Tomatina... imagens, textos assim para mostrar e eles conhecerem, porque o visual também chama a atenção, desperta curiosidade e ajuda. [P1]

Enfim ... isso é através de buscar realizar aulas dinâmicas ... como eu disse ... Eu gosto de trabalhar com gincana (brincadeiras) músicas... isso é fantástico. Quando você leva uma música, explora, canta com eles, trabalha a questão gramatical ... é fundamental e eles aprendem. [P1]

Sin embargo, los informantes que se sitúan en las escuelas de Perú y Bolivia declaran que no disponen de tantos recursos. Igualmente declaran que tienen dificultades para utilizar los recursos tecnológicos:

[...] los recursos materiales son los más comunes [...] no estoy preparado todavía... para utilizar internet, en el aula, hay que tener una capacitación para utilizar un medio tecnológico como red sociales... [P2].

Finalmente, reconocen que el papel del profesor de lenguas está más allá de ser un mero transmisor de contenidos. Creen que deben actuar como mediadores en las situaciones de conflicto en el aula, tratando de establecer un diálogo entre el alumnado para garantizar la convivencia pacífica entre ellos:

O professor, na verdade, ele tem que ser mediador, analisar e procurar cohibir estes tipos de situações. Em momento algún o professor tem que ser ... às vezes, passivo com esses tipos de atitudes. Porque eu, particularmente, já vivi isso. Já estudei no Peru, e de alguma forma, eu era uma vítima de preconceito também. [P1]

Soy paralelo, lineal, entre ambos estudiantes... No... favoreciendo ni a uno ni a otro sino, pues creando una comunicación en el marco del respeto. Los estudiantes... pues... la mejor manera para poder ... bueno, 
estar... con los estudiantes es saber escucharles también. Escuchar y saber qué es lo que piensan cada uno de ellos... y esto me llena de satisfacción, pues... que sean conscientes, que sean sinceros en el momento de conversar, de hablar o decir una verdad. [P2]

Con respecto a la categoría compromiso como docente, los informantes declaran que buscan desarrollar en sus estudiantes capacidades que van más allá del aprendizaje de la lengua. Según manifiestan, su actuación está orientada a un planteamiento de enseñanza de lenguas donde se tengan en cuenta valores, como la aceptación del otro y el desarrollo de actitudes de respeto hacia la diversidad:

Em alguns momentos se dão estas situações de preconceitos como temos aqui, por exemplo: muitos alunos peruanos e bolivianos e se cria esta situação de não aceitar o outro como ele é. E ai o que eu coloco é que... ele sempre deve se colocar no lugar do outro... ele deve viver esta situação para ver como eles se setiriam, não é ?Mas é tratar mesmo de conscientizar a este cidadão a não reagir contra esta diversidade. Aceitar o próximo como a si mesmo. [P1]

De certo modo, quando colocamos... hoje o ensino de linguas não é exatamente ofalar, saber se expressar em espanhol ou inglês ou qualquer outro idioma... Mas que é ele, a partir do conhecimento que ele tem e o domínio desta língua, ele se comunicar com estas diversas culturas, respeitar... Hoje uma das questões que temos que mais valorizar é esta questão da cultura mesmo de cada povo, de cada... Porque a partir do momento que você conhece isto você passa a valorizar, não é? Y você passa a entender ao outro desta forma também. [P1]

Además de fomentar actitudes hacia el otro, los docentes expresan que buscan desarrollar en sus alumnos actitudes favorecedoras de un aprendizaje autónomo de las lenguas y culturas:

Sim. Sempre coloco que devemos ter disciplina, um projeto de vida. Porque quando você planeja e você almeja um alvo, você precisa traçar planos e se esforçar para isso ... Então, eu sempre coloco esta situação, não é? Qual cidadão ele quer ser amanhã? E para isso ele terá que desenhar metas para conquistar tudo isso ... é com grande esforço e uma das situações é ele abraçar a causa e despertar o interesse, ser autodidata, ter tempo, buscar ter tempo para estudar, porque só a escola também não é suficiente ... existem outras fontes, há a internet, que ele use aplicativos de telefone, que consiga aprender. [P1] 
Enseñándoles, otorgándoles los medios por los cuales tiene que estudiar una carrera y que la carrera les va a enseñar, les va a obligar aprender otras lenguas... dándoles, mostrándoles el camino, la profesión que ellos van a tener que lograr. [P2]

Qué lo practiquen. Siempre... Que lo lleven como ejemplo, para ir practicando en su vida cotidiana. Que traten de familiarizar más que todo con eso. De que vivencia a diario... A veces digo también, ¿no? A veces les digo en quechua... a diario les voy hablando. Así ellos van aprendiendo... constantemente. [P3]

Con respecto a la categoría relación que establece con el alumno, los datos revelan que los docentes buscan establecer una relación interactiva entre docente y discentes. Señalan que entablan una comunicación basada en el diálogo y en el marco del respeto, siempre buscando favorecer la interacción con el alumnado y construir vínculos afectivos entre profesor y alumnos:

[...] Eu sou um professor que sempre busco atuar com discernimento e através do diálogo com meus alunos. [P1]

Pues a mi parecer ... el diálogo. El diálogo entre estudiantes y profesor es lo primero. Lo que hago es, primeramente, antes del inicio de la gestión, es realizar una conversación amena con los estudiantes... y los estudiantes entre estudiantes, para que se puedan conocer a si mismo, pueda interactuar sobre su diario vivir... [P2]

Bueno... Yo... tratarme de adecuar a la realidad de ellos. Tratar de ver... yo también ponerme en su posición... de ellos. Ver de qué manera... ¿no? Comprenderlos. Porque ellos son adolescentes y también no se les puede... como se dice: reprenderlos. Tratar de ponerme en su lugar $y$ tratar de entenderlos... pero no dejar que sobrepasen en algunos términos... Buscando la amistad. Ser amigo de ellos... bueno... [P3]

En cuanto a la categoría implicación con la comunidad escolar, los informantes declaran que sí participan en las actividades que realiza su centro educativo. Según expresan, participan en proyectos del centro educativo orientados a combatir prejuicios. También actúan en la logística de sus centros, como se puede ver en las siguientes afirmaciones:

E isso aí, por exemplo, em sala de aula, trato de amenizar muito, mesmo porque aqui muitos estudantes, por exemplo, vêm do Peru desde a préescola e quando não é trabalhado... a escola até desenvolveu um projeto sobre preconceitos nesta situação, porque tem o indígena também, que é vítimas desta situação ... [P1] 
Y no sé si usted ha dado cuenta de que en algunas aulas no tenemos carpetas (se refiere a mesas y sillas)... nosotros hemos tenido que venir a clavar las carpetas... recoger pedazos por pedazos para que puedan los alumnos estudiar. [P3]

Asimismo, los datos revelan que los docentes interactúan y colaboran con sus pares en la planificación de las secuencias didácticas, ya sea con aquellos docentes del área de lenguas o de otras materias.

Geralmente os de linguas têm estas trocas de ideias, trocamos diferentes pontos de vista onde colocamos a melhor forma de trabalhar determinados conteúdos. [P1]

A inicio de gestión tenemos una reunión ... ya de planificación. Y esta planificación consiste en que cada uno de los profesores aporta ideas para la planificación que se va a llevar a cabo durante todo el año [...] entonces... si hay una comunicación entre los profesores, una coordinación para plantear las actividades y presentar en una fecha determinada. [P2]

Si. Nosotros trabajamos... primero tenemos que hacer nuestra diversificación curricular, ¿no? Y con eso nosotros tratamos... Yo, por ejemplo, en mi área puedo tratar sobre lenguas... a veces el profesor de Artes que trabaja en otras áreas más que contextualizamos con nuestra área. Tenemos que trabajar... acogernos a eso. Todos nos juntamos, nos reunimos... que es lo que vamos a tratar, ¿no? El tema y de qué manera... y asi trabajamos. [P3]

Según se expresan esos profesionales, el trabajo colectivo se concibe como importante porque todos aportan conocimientos, lo que les permite aprender con sus compañeros de trabajo. Esta afirmación la evidenciamos en la siguiente declaración:

E com esse trabalho mais coletivo é bom porque temos aqui um professor que é peruano e trabalha com a língua espanhola ... Isso é ... e para quem é daqui tem a oportunidade de aprender mais. assim como ele tem algumas dúvidas ... mas é bem legal ... aprendemos bastante. [P1]

\section{Resultados y conclusiones}

Los resultados del análisis revelan que los docentes de lenguas del contexto transfronterizo son conscientes de las potencialidades del propio contexto en la construcción de su identidad profesional. El hecho de que saquen partido de la 
pluralidad lingüístico-cultural de sus aulas para potenciar el aprendizaje de sus alumnos, movilizando sus repertorios lingüísticos y haciéndoles conscientes de la importancia de aprender lenguas, muestra unas prácticas pedagógicas orientadas hacia planteamientos de educación plurilingüe.

Aunque los docentes comparten con el alumnado en el aula las lenguas maternas presentes en el aula, no es común el uso de prácticas en las que se realizan análisis y comparaciones de diferentes lenguas, en especial aquellas que no hacen parte de esta realidad lingüístico-cultural.

Asimismo, se observa que los docentes ponen en funcionamiento prácticas de aula orientadas a la construcción de valores, por ejemplo cuando intervienen como mediadores para solucionar los conflictos que surgen en el aula. Bajo esta práctica subyace un interés por una educación que contribuya a que sus estudiantes sean respetuosos y tolerantes y sean conscientes del valor que tiene el otro, aceptando de forma positiva esta diversidad.

Esas iniciativas son esenciales para promocionar el desarrollo de la competencia plurilingüe del alumnado, puesto que esta competencia requiere, no solo de una capacidad para hacer uso del repertorio lingüístico, sino también de una capacidad para un "bienvivir" con otros, tal como se señala en los documentos del Consejo de Europa que abordan el concepto de plurilingüismo.

En cuanto a la gestión para la integración del aula de lenguas y la comunidad escolar, podemos concluir que el perfil del profesor de lenguas del contexto transfronterizo se caracteriza por la naturaleza relacional de este profesional, cuando este es consciente de que el suceso de su trabajo está condicionado por las relaciones que este establece tanto en el aula, entre los docentes y discentes, así como entre sus pares en la comunidad escolar.

\section{Contribución del trabajo}

El presente estudio nos ha permitido comprobar que existen elementos de educación plurilingüe en el perfil profesional de un grupo de profesores de lenguas que sitúan sus prácticas en un contexto transfronterizo. Identificar estos rasgos en su perfil nos ha servido para comprender las acciones que realizan en el aula desde la perspectiva de una educación plurilingüe. De este modo, esta investigación servirá para reflexionar sobre las potencialidades que ofrecen el contexto transfronterizo, peculiar por su naturaleza de súper diversidad, para la construcción de una identidad profesional del docente que atienda a la educación plurilingüe. 
DINIZ, M.; PRIETO, P. Research on language teaching in a cross-border context: analysis of the professional language teacher profile. Alfa, São Paulo, v.62, n.2, p.345-360, 2018.

- ABSTRACT: In the process of building teachers 'professional identity, social and professional practices play an important role. Those practices are, however, affected by the context in which they are immersed. For the aim of this paper, we locate our research on the cross-border region Brazil-Peru-Bolivia to analyse teachers' professional profile. The purpose of our analysis is to identify elements of plurilingual competence in their professional profile. It will allow us to reflect on the potentialities offered by a cross-border context in the process of building a professional identity of teachers from the perspective of plurilingual education. We locate our research in the field of Didactic of Language and Literature to address key concepts related to plurilingual education. We have identified that teachers are aware of the potentiality of the context and they develop pedagogical practices that contribute to the development of plurilingual competence.

- KEYWORDS: Professional identity. Cross-border contexts. Language teacher. Plurilingual education.

\section{REFERÊNCIAS}

ARTAVIA, J. M. Interacciones personales entre docentes y estudiantes en el proceso de enseñanza y aprendizaje. Revista Electrónica Actualidades Investigativas en Educación, Costa Rica, v. 5, n. 2, p. 1-19, 2005.

BALDUZZI, M.; EGLE, R. Representaciones sociales e ideología en la construcción de la identidad profesional de estudiantes universitarios avanzados. Revista Intercontinental de Psicología y Educación, México, v. 12, n. 2, p. 65-68, 2010.

ARRIAGA-RODRÍGUEZ, J. C. El concepto frontera en la geografía humana. Perspectiva Geográfica, Boyacá, v. 17, p. 71- 97, 2012.

BARDIN, L. Análisis de contenido. Madrid: Akal, 1986.

BATTHYÁNY, K.; CABRERA, M. (Coord.). Metodología de la investigación en Ciencias Sociales: apuntes para un curso inicial. Montevideo: Universidad de la República, 2011.

BAUMAN, Z. Identidade: entrevista a Benedetto Vecchi. Rio de Janeiro: J. Zahar, 2005.

BEACCO, J. C.; BYRAM, M. Guide for the development of language education policies in Europe. Strasbourg: Council of Europe, 2007. Disponible en: $<\mathrm{http}: / / \mathrm{www}$. coe.int/t/dg4/linguist>. Acceso em: 18 mayo 2014.

BISQUERRA, R. A. (Coord.). Metodología de la investigación educativa. Madrid: Editorial La Muralla, 2014. 
CONSEJO DE EUROPA. Marco común europeo de referencia para las lenguas: aprendizaje, enseñanza, evaluación: MCERL. (versión castellana). Madrid: Instituto Cervantes, 2002.

FERNÁNDEZ TILVE, M. D.; MALVAR MÉNDEZ, M. L. La colaboración em lós centros educativos: una oportunidad de aprendizaje profesional. Revista Curriculum y Formación de Profesorado, Granada, v. 3, n. 1, p. 1-6, 1999.

FLICK, U. El diseño de investigación cualitativa. Madrid: Morata, 2015.

HALL, S.; SILVA, T. T.; LOURO, G. L. A identidade cultural no pós-modernidade. 11.ed. Rio de Janeiro: DP\&A, 2006.

KVALE, S. Las entrevistas en investigación cualitativa. Madrid: Ediciones Morata, 2011.

MORALES ORTEGA, A. Identidad e inmigración: análisis de las identidades colectivas de los inmigrantes a través de entidades y organizaciones sociales. 2016. 93f. Treballs Finals (Del Grau de Sociologia) - Facultat d'Economia i Empresa, Universitat de Barcelona, 2016. Disponible en: <http://diposit.ub.edu/dspace/ bitstream/2445/101622/1/TFG-SOC-Morales-Andres-juliol16.pdf>. Acceso: 11 fev. 2017.

NUSSBAUM, L.; UNAMUNO, V. Luces y sombras de la educación plurilingüe en España y América Latina. In: LOMAS, C. et al. (Ed.). La educación lingüística, entre el deseo y la realidad: competencias comunicativas y enseñanza del lenguaje. Barcelona: Ediciones Octaedro, 2014. p. 203-215.

PERRENOUD, P. Desarrollar la práctica reflexiva en el oficio de enseñar: profesionalización y razón pedagógica. Barcelona: Grao de Irif, 2007.

PIÑEIRO, M. G.; GUILLÉN, C. D.; VEZ, J. M. Didáctica de las lenguas modernas: competencia plurilingüe e intercultural. Madrid: Síntesis, 2010.

RICHARDS, L. E. La interacción profesor-alumno: una visión desde los procesos atribucionales. Psicoperspectivas, Chile, v. IV, p. 57-73, 2005. Disponible en $<$ http:// psicoperspectivas.cl/index.php/psicoperspectivas/article/viewFile/26/26>. Acceso en: 20 agosto 2017.

STRAUSS, A. L.; CORBIN, J. Basis of qualitative research. Londres: Sage, 1990.

TRAVER MARTÍ, J. A. Implicación y compromiso docente en la enseñanza secundaria. Edetania, [S.1.], v.39, p. 89-98, 2011.

Recebido em 30 de agosto de 2017

Aprovado em 22 de março de 2018 